\title{
The neural correlates of reward-related trial-and-error learning: An fMRI study with a probabilistic learning task
}

\author{
Kathrin Koch, ${ }^{1,3}$ Claudia Schachtzabel, ${ }^{1}$ Gerd Wagner, ${ }^{1}$ Jürgen R. Reichenbach, ${ }^{2}$ \\ Heinrich Sauer, ${ }^{1}$ and Ralf Schlösser ${ }^{1}$ \\ ${ }^{1}$ Department of Psychiatry and Psychotherapy, Friedrich-Schiller University Jena, 07740 Jena, Germany; ${ }^{2}$ Medical Physics Group, \\ Institute for Diagnostic and Interventional Radiology, Friedrich-Schiller University Jena, 07740 Jena, Germany
}

This fMRI study investigated the neural correlates of reward-related trial-and-error learning in association with changing degrees of stimulus-outcome predictabilities. We found that decreasing predictability was associated with increasing activation in a frontoparietal network. Only maximum predictability was associated with signal decreases across the learning process. The receipt of monetary reward revealed activation in the striatum and associated frontoparietal regions. Present data indicate that during reward-related learning, high uncertainty forces areas relevant for cognitive control to remain activated. In contrast, learning on the basis of predictable stimulus-outcome associations enables the brain to reduce resources in association with the processes of prediction.

Being able to learn from feedback or reward and to adapt behavior accordingly is an important capability in everyday life. There is increasing evidence that the mesolimbic dopamine system (MDS) is critically involved in the processing of reward and reward-related learning (Elliott et al. 2003; McClure et al. 2003). Activation in orbital/medial frontal and MDS regions has been found to be inversely related to the likelihood to receive positive feedback or reward (Pagnoni et al. 2002; McClure et al. 2003). Therefore, activation in these regions is assumed to constitute the neural correlate of the so-called prediction error that describes the difference between the expected and the received outcome or reward (Schultz and Dickinson 2000; Waelti et al. 2001).

While anatomical knowledge about the areas involved in reward-related learning is increasing, comparably little is known about the underlying activation dynamics. In the context of short-term memory, learning with and without reinforcement has been found to go along with practice-associated activation decreases (Milham et al. 2003; Delgado et al. 2005; Koch et al. 2006). These decreases are assumed to reflect a learning-related increase in automated processing, demanding fewer processing resources. The association between these learning-related activation dynamics and the dynamics of the environment is still rather unknown, however.

In the present study, we aimed to investigate reward-related learning in a dynamic environment by varying the predictability of a consequence. Three conditions were employed: allowing no predictability (50\% stimulus-outcome-contingency), full predictability (100\% stimulus-outcome-contingency), and medium predictability (69\% stimulus-outcome-contingency).

Assuming that in the $50 \%$ condition reinforcement-related learning should be impossible, we expected to find no learningassociated signal decreases in this condition, whereas for the $100 \%$ condition, we expected automated processing to occur rather fast. The direct comparison of all predictability conditions should therefore yield a negative relation between activation intensity and predictability in areas shown to be responsible for controlled

\footnotetext{
${ }^{3}$ Corresponding author.
}

E-mail kathrin.koch@med.uni-jena.de; fax 49-3641-9-35444.

Article is online at http://www.learnmem.org/cgi/doi/10.1101//m.1106408. cognitive processing (Ridderinkhof et al. 2004; Carter and van Veen 2007). Finally, the positive prediction error was expected to be reflected in specific reward-associated activation in mainly the MDS and frontal regions (Abler et al. 2006; Heekeren et al. 2007; Yacubian et al. 2007).

\section{Results}

\section{Behavioral data}

Analyses of the percentage of correct reactions yielded $87.7 \% \pm 12.6 \%$ (100\% condition), $59.5 \% \pm 25.5 \%$ (69\% condition), and $48.3 \% \pm 14.5 \%$ (50\% condition). The repeatedmeasures ANOVA revealed a significant main effect $\left(F_{(1.6,50.1)}=37.8, P<0.001\right)$, indicating significant differences among the three probability conditions.

The analysis of the learning rate constant for the $100 \%$ condition yielded a $p_{3}$ of $1.1\left(\mathrm{R}^{2}=0.40, \mathrm{CI}_{95 \%}=-0.06-2.32\right)$, indicating a fast performance improvement and a sensible model fit. The analysis of the learning rate constant for the $69 \%$ condition yielded a $p_{3}$ of $1.6\left(\mathrm{R}^{2}=0.43, \mathrm{CI}_{95 \%}=0.09-3.05\right)$, suggesting a slightly slower improvement than in the $100 \%$ condition. For the $50 \%$ condition, the data did not converge with the model of an exponential increase, indicating a complete lack of a learningassociated exponential decrease in response times.

\section{FMRI data}

\section{Probability-associated activation}

Analyses of probability-specific activation yielded activation in mainly frontal and parietal regions and smaller activation in temporal and occipital areas in all conditions $(P<0.05$ FWE corrected) with the most extensive activation patterns in the $50 \%$ condition (Fig. 1).

Comparing the different probability conditions, we found the medial frontal gyrus (BA 10) $(x=-6, y=44, z=-10$, $k=319, T=5.89, x=-8, y=55, z=3, k=55, T=4.87)$ to be activated in association with increasing predictability (Fig. 2A). In addition, there was significant activation in the right middle/ superior temporal gyrus $(x=48, y=-54, z=5, k=21, T=4.15$, $x=63, y=-3, z=9, k=81, T=4.55)$. The opposite contrast (i.e., 


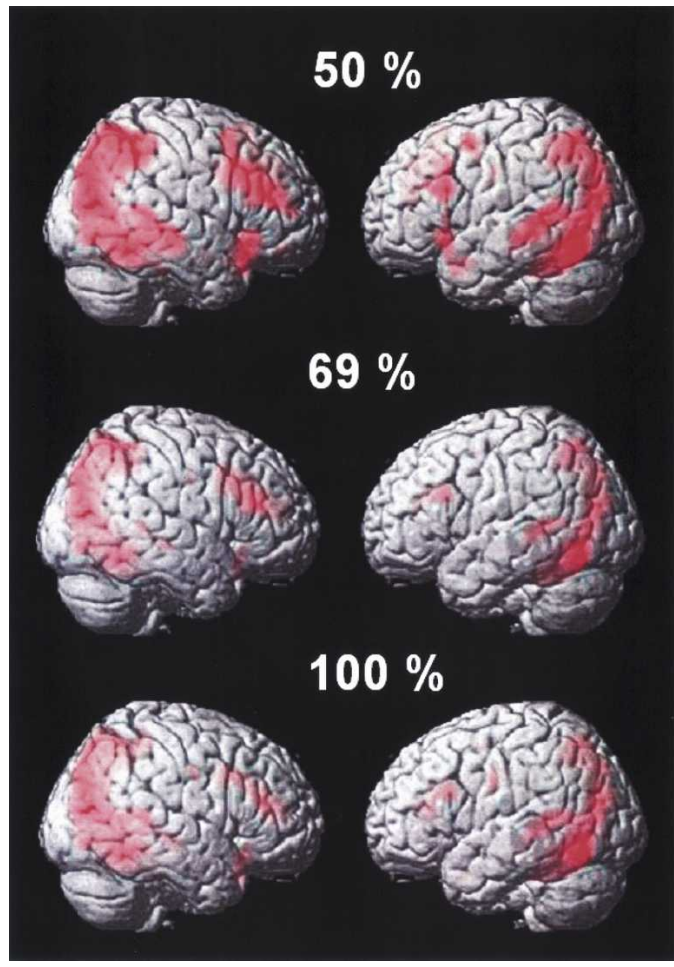

Figure 1. Activation patterns for each probability condition at $P<0.05$ FWE corrected.

$50 \%>69 \%>100 \%$ ) yielded widespread activation in the frontal cortex (BA 6, 9, 47, 11) and the right inferior parietal (BA 40) lobe (Table 1; Fig. 2B).

\section{Probability-associated exponential signal decrease}

Analyzing the probability-associated signal decrease, we found significant results only for the $100 \%$ condition in a frontoparieto-temporal network (BA 6, 8/9, BA 40, BA 22) (Table 2).

\section{Positive feedback/reward-associated activation}

Analysis of the reward-related prediction error resulted in significant activations mainly in a fronto-parieto-striatal network (BA 6, 9, 10, 40, 7) (Table 3; Fig. 3). Analysis of the time-invariant, reward-related activation yielded activation in mainly frontal, temporal, and occipital areas, as well as the ventral striatum (n. accumbens) (Table 4; Fig. 3).

\section{Discussion}

As a main finding, we detected increasing activation in a rightlateralized, frontoparietal network in association with linearly decreasing predictability. In addition, a learning-related signal decrease in a network of task-relevant regions was observable only in the condition with the highest predictability.

Hence, the $100 \%$ probability condition was expectedly associated with a rapidly automated processing, indicating that stimulus contingencies were rapidly identified. This fast increase in automated processing resulted in activation decreases in DLPFC (BA 8/9) and dACC (BA 32). These are areas that are known to decrease in activity with increasingly automated processing (Milham et al. 2003; Koch et al. 2006). Activation decreases were moreover detectable in the middle temporal and parahippocampal gyrus-areas involved in short- and mediumterm memory processing (Sakai and Passingham 2004; Hasselmo and Stern 2006). These decreases indicate that memory-related

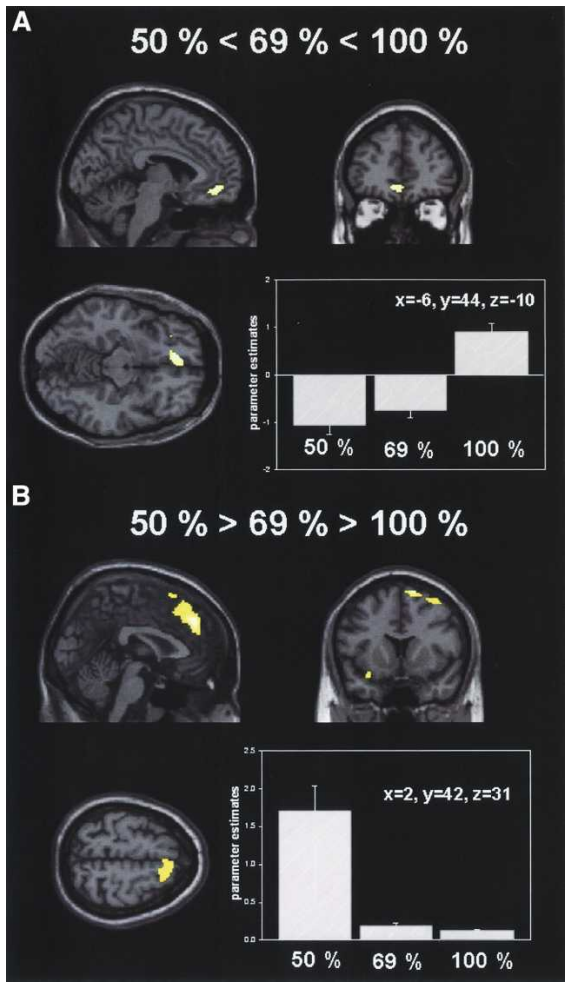

Figure 2. (A) Differences in activation in the medial frontal gyrus (BA 10) for the comparison $50 \%<69 \%<100 \%$ at $P<0.05$ FDR corrected. $(B)$ Differences in activation in a frontoparietal network for the comparison $50 \%>69 \%>100 \%$ at $P<0.05$ FDR corrected.

processes become increasingly dispensable as soon as the stimulus-outcome association has been identified.

The lack of any learning effect in the $50 \%$ condition (which was likewise reflected by the lack of response time decreases) is according to expectation. Consequently, the direct comparison of all probability conditions yielded increased activation in association with decreasing predictability in a mainly rightlateralized, frontoparietal network, including right DLPFC (BA 9), VLPFC bilaterally (BA 47), right OFC (BA 11), and right inferior parietal lobe (BA 40). Activation in the DLPFC has frequently been found in association with highly uncertain decisions (Huettel et al. 2005; Satterthwaite et al. 2007). Likewise, in a preceding study, we found VLPFC and inferior parietal lobe to be activated during controlled as opposed to automatic processing (Koch et al. 2006). The parietal activation moreover concurs with the findings by Delgado et al. (2005), who also reported activation increases in the inferior parietal cortex that were largest in the $50 \%$ condition. In contradiction to the dorsolateral and ventrolateral prefrontal activation that can be assumed to be as-

Table 1. Talairach coordinates of activation maxima (SPM $\{T\}$ value) for the comparison between the different probabilities $(50 \%>69 \%>100 \%)$ at $P<0.05$ FDR corrected

\begin{tabular}{lccrrrr}
\hline Region & Side & $\begin{array}{c}\text { SPM } \\
\{\text { T }\}\end{array}$ & \multicolumn{1}{c}{$\boldsymbol{x}$} & $\boldsymbol{y}$ & \multicolumn{1}{c}{$\boldsymbol{z}$} & \multicolumn{1}{c}{$\boldsymbol{k}$} \\
\hline Medial frontal gyrus, BA 6 & $\mathrm{r}$ & 5.59 & 2 & 42 & 31 & 1045 \\
Inferior frontal gyrus, BA 47 & $\mathrm{r}$ & 5.08 & 36 & 19 & -6 & 244 \\
Inferior frontal gyrus, BA 47 & $\mathrm{I}$ & 4.35 & -34 & 19 & -6 & 53 \\
Superior frontal gyrus, BA 11 & $\mathrm{r}$ & 4.68 & 34 & 52 & -13 & 24 \\
Middle frontal gyrus, BA 9 & $\mathrm{r}$ & 3.76 & 38 & 12 & 51 & 64 \\
Inferior parietal lobe, BA 40 & $\mathrm{r}$ & 4.86 & 50 & -48 & 43 & 230 \\
\hline
\end{tabular}


Table 2. Talairach coordinates of activation maxima (SPM $\{T\}$ value) for the exponential signal decrease in the $100 \%$ probability condition at $P<0.05$ FDR corrected

\begin{tabular}{lccrrrr}
\hline & \multicolumn{2}{c}{ SPM } & & & & \\
Region & Side & $\{$ T $\}$ & \multicolumn{1}{c}{$\boldsymbol{x}$} & $\boldsymbol{y}$ & $\boldsymbol{z}$ & $\boldsymbol{k}$ \\
\hline Superior frontal gyrus, BA 6 & $\mathrm{I}$ & 5.94 & -16 & 18 & 56 & 233 \\
Superior frontal gyrus, BA 8/9 & $\mathrm{r}$ & 4.58 & 24 & 32 & 48 & 167 \\
Middle frontal gyrus, BA 8 & $\mathrm{r}$ & 4.28 & 40 & 27 & 39 & 71 \\
Middle frontal gyrus, BA 8 & $\mathrm{I}$ & 3.81 & -28 & 20 & 41 & 15 \\
Superior frontal gyrus, BA 8 & $\mathrm{I}$ & 3.8 & -4 & 34 & 52 & 13 \\
Inferior frontal gyrus, BA 13 & $\mathrm{r}$ & 4.78 & 32 & 11 & -9 & 37 \\
Anterior cingulate, BA 32 & $\mathrm{r}$ & 4.71 & 18 & 39 & 11 & 39 \\
Parahippocampal gyrus & $\mathrm{I}$ & 4.9 & -30 & -60 & 10 & 99 \\
Inferior parietal lobe, BA 40 & $\mathrm{r}$ & 4.35 & 55 & -54 & 38 & 202 \\
Precuneus, BA 7 & $\mathrm{r}$ & 4.05 & 10 & -56 & 38 & 24 \\
Middle temporal gyrus, & $\mathrm{r}$ & 4.85 & 52 & -35 & -2 & 78 \\
$\quad$ BA 22 & & & & & & \\
Transverse temporal gyrus, & $\mathrm{r}$ & 4.24 & 34 & -29 & 7 & 18 \\
$\quad$ BA 41 & & & & & & \\
Middle temporal gyrus, & $\mathrm{I}$ & 4.37 & -63 & -31 & 2 & 49 \\
$\quad$ BA 22 & & & & & & \\
\hline
\end{tabular}

sociated with increased cognitive demands, the orbitofrontal activation that we found is more likely to be affect related. Thus, the impossibility to properly predict a consequence might have caused a negative effect that has been found to go along with OFC activation (Damasio et al. 2000; Koch et al. 2007a).

Analysis of increased activation in association with increasing predictability revealed extended activation in the medial prefrontal cortex (MPFC; BA 10) (see also Fig. 2A). This area constitutes a central component of the mesolimbic pathway. Recent work attributes to the MPFC a specific role in association with the processing of reward (Daw et al. 2006; O'Doherty et al. 2007), assuming that it encodes the rewarding value of a chosen action. As in the $100 \%$ condition the confidence to react correctly and receive a future reward was prevalent early present data support this recent concept.

Interestingly, the positive prediction error yielded medial and lateral frontal (BA 6/9/10) as well as MDS activation in the dorsal striatum bilaterally, as has been shown before (Aron et al. 2004; Abler et al. 2006; Yacubian et al. 2006). Multiple studies revealed involvement of the dorsal striatum in the processing of reward (Delgado et al. 2000; Nieuwenhuis et al. 2005; Tricomi et al. 2006). Delgado et al. (2005) also found reward-related signal in the dorsal striatum, which decreased as learning progressed.

Table 3. Talairach coordinates of activation maxima (SPM $\{T\}$ value) for the prediction error (i.e., linearly decreasing activation during positive feedback/reward) at $P<0.05$ FDR corrected

\begin{tabular}{lccrrrr}
\hline Region & Side & $\begin{array}{c}\text { SPM } \\
\{\text { T }\}\end{array}$ & \multicolumn{1}{c}{$\boldsymbol{x}$} & $\boldsymbol{y}$ & $\boldsymbol{z}$ & $\boldsymbol{k}$ \\
\hline Medial frontal gyrus, BA 6 & $\mathrm{I}$ & 4.21 & -4 & 27 & 37 & 292 \\
Medial frontal gyrus, BA 6 & $\mathrm{I}$ & 3.01 & -16 & 6 & 48 & 60 \\
Medial frontal gyrus, BA 6 & $\mathrm{I}$ & 3.68 & -34 & -1 & 57 & 35 \\
Middle frontal gyrus, BA 9 & $\mathrm{I}$ & 4.81 & -50 & 8 & 35 & 428 \\
Middlle frontal gyrus, BA 9 & $\mathrm{r}$ & 4.74 & 48 & 11 & 33 & 334 \\
Middle frontal gyrus, BA 9 & $\mathrm{I}$ & 4.54 & -44 & 27 & 26 & 70 \\
Middlle frontal gyrus, BA 10 & $\mathrm{I}$ & 5.14 & -38 & 49 & 10 & 364 \\
Midddle frontal gyrus, BA 10 & $\mathrm{r}$ & 3.68 & 46 & 46 & 16 & 43 \\
Middlle frontal gyrus, BA 10 & $\mathrm{r}$ & 4.33 & 36 & 57 & 5 & 295 \\
Superior parietal lobe, BA 7 & $\mathrm{I}$ & 4.57 & -14 & -61 & 58 & 908 \\
Inferior parietal lobe, BA 40 & $\mathrm{I}$ & 4.48 & -40 & -47 & 41 & 531 \\
Inferior parietal lobe, BA 40 & $\mathrm{r}$ & 4.19 & 40 & -56 & 45 & 245 \\
Caudate body & $\mathrm{I}$ & 4.17 & -18 & 1 & 22 & 83 \\
Caudate body & $\mathrm{r}$ & 3.82 & 16 & -3 & 24 & 58 \\
Caudate head & $\mathrm{r}$ & 4.03 & 10 & 23 & 3 & 190 \\
Caudate head & $\mathrm{I}$ & 3.96 & -14 & 24 & 6 & 105 \\
\hline
\end{tabular}

Table 4. Talairach coordinates of activation maxima (SPM $\{T\}$ value) for positive feedback/reward (i.e., time-invariant activation) at $P<0.05$ FDR corrected

\begin{tabular}{|c|c|c|c|c|c|c|}
\hline Region & Side & $\begin{array}{c}\text { SPM } \\
\{T\}\end{array}$ & $x$ & $y$ & $z$ & $k$ \\
\hline $\begin{array}{l}\text { Middle frontal gyrus, } \\
\text { BA } 46\end{array}$ & $\mathrm{r}$ & 5.61 & 54 & 34 & 24 & 1520 \\
\hline $\begin{array}{l}\text { Middle frontal gyrus, } \\
\text { BA } 10\end{array}$ & I & 5.22 & -40 & 55 & 8 & 3041 \\
\hline $\begin{array}{l}\text { Middle frontal gyrus, } \\
\text { BA } 11\end{array}$ & $\mathrm{r}$ & 3.71 & 26 & 42 & -14 & 58 \\
\hline $\begin{array}{l}\text { Middle frontal gyrus, } \\
\text { BA } 6\end{array}$ & $r$ & 4.05 & 34 & 11 & 57 & 227 \\
\hline $\begin{array}{l}\text { Superior frontal gyrus, } \\
\text { BA } 6\end{array}$ & I & 3.96 & -2 & 7 & 64 & 151 \\
\hline $\begin{array}{l}\text { Medial frontal gyrus, } \\
\text { BA } 8\end{array}$ & I & 4.82 & -2 & 27 & 37 & 706 \\
\hline $\begin{array}{l}\text { Posterior cingulate, } \\
\text { BA } 23\end{array}$ & I & 3.56 & 0 & -36 & 24 & 100 \\
\hline Putamen & $\mathrm{r}$ & 3.19 & 20 & 15 & -8 & 35 \\
\hline Nucleus accumbens & $\mathrm{r}$ & 2.75 & 6 & 2 & -4 & 33 \\
\hline $\begin{array}{l}\text { Superior temporal gyrus, } \\
\text { BA } 22\end{array}$ & $r$ & 3.27 & 55 & -29 & 3 & 106 \\
\hline $\begin{array}{l}\text { Middle temporal gyrus, } \\
\text { BA } 22\end{array}$ & I & 2.95 & -48 & -44 & 10 & 49 \\
\hline $\begin{array}{l}\text { Cerebellum, occipital } \\
\text { cortex, BA } 18 / 19\end{array}$ & $r$ & 9.31 & 36 & -54 & -22 & 25,117 \\
\hline
\end{tabular}

Thus, our findings are in compliance with Delgado et al. (2000, 2005) and the assumption that dorsal striatal activation decreases with decreasing difference between the expected and the received outcome or reward (Waelti et al. 2001). Interestingly, activation in the ventral striatum (n. accumbens) was only detectable when analyzing the time-invariant, reward-related activation. This finding is in concordance with results by Delgado and colleagues $(2000,2005)$, who likewise reported invariant $n$. accumbens activation when contrasting rewards and punishments. Present data, as well as those by Delgado et al., suggest that $\mathrm{n}$. accumbens activation might be rather stable across time.

Besides reward-characteristic activation in the frontopolar region (BA 10) (Knutson et al. 2003; Hornak et al. 2004), the positive prediction error yielded activation in the middle frontal gyrus (BA 9) and inferior/superior parietal lobe (BA 7/40). This

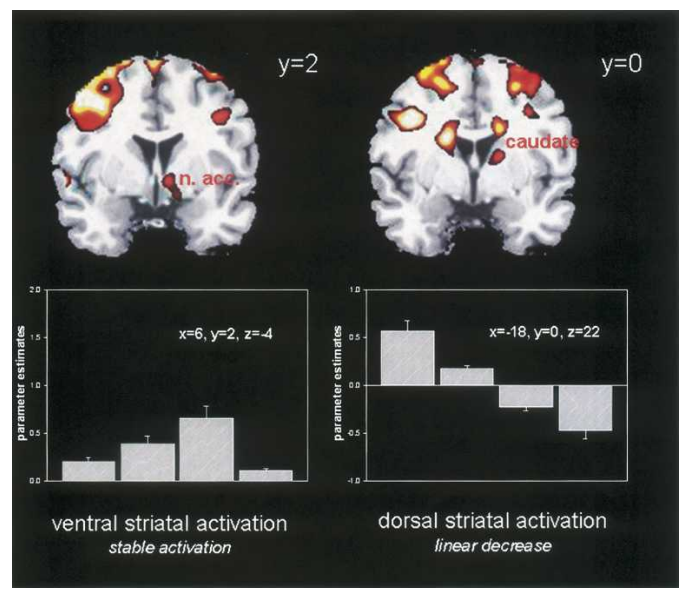

Figure 3. Reward-related activation in the ventral striatum (n. accumbens; left) modeled in a time-invariant fashion (i.e., stable activation during positive feedback/reward), and the dorsal striatum (caudate; right) modeled in accordance with a prediction-error associated decrease in activation (i.e., linearly decreasing activation during positive feedback/ reward). 
working memory-characteristic frontoparietal network reflects the high information content of positive feedback at the beginning of the learning process, which is known to constitute the prerequisite for proper response adaptation.

\section{Materials and Methods}

\section{Subjects}

The study included 28 right-handed (Oldfield 1971) students from the University of Jena (11 male, 17 female). Participants were $24.6 \pm 5.5 \mathrm{yr}$ old. They were screened by comprehensive assessment procedures for medical, neurological, and psychiatric history. Exclusion criteria were current and potentially interfering medical conditions, any current or previous neurological or psychiatric disorder, and first-degree relatives with axis I psychiatric or neurological disorders.

\section{Experimental design}

An event-related, trial-and-error learning task was applied (Delgado et al. 2005). Participants were informed that they were presented a card with a geometrical figure on it (triangle, pentagon, circle, square, half-moon, or cross). They were told that each figure was associated with an unknown value ranging from one to nine. Participants were asked to guess whether the figure predicted a value higher or lower than the number five and were told that each correct guess was followed by a monetary consequence (correct guess: $+0.50 €$; wrong guess: $-0.50 €$ ). Participants were also instructed that each figure predicted the respective value with a certain probability. Predictive probabilities were $50 \%, 69 \%$, and $100 \%$. Participants were not informed about the predictive probabilities of the figures. The whole paradigm contained 96 interleaved trials (16 trials per probability condition). Each trial started with the presentation of the probability condition-specific figure for $1.5 \mathrm{sec}$. After a 4.5 -sec interstimulus interval, a question mark was presented for $2.5 \mathrm{sec}$, during which time the participants had to answer by button press. After another interstimulus interval of $4.5 \mathrm{sec}$, the correct solution followed by the indication of a reward or punishment appeared for $2.5 \mathrm{sec}$.

Participants were compensated according to their performance, although the minimum of $€ 20$ was guaranteed for volunteering.

Each trial ended with an intertrial interval lasting $3.5 \mathrm{sec}$. In addition, we introduced a temporal jitter by varying the second interstimulus interval between 4.5 and $5.5 \mathrm{sec}$ (i.e., $4.5 \mathrm{sec}$ plus $0-1000-m s e c$ jitter) in order to increase sensitivity.

\section{fMRI procedure}

Functional data were collected on a 3 T Siemens TIM Trio whole body system (Siemens) equipped with a 12-element, receive-only head matrix coil. Foam pads were used for positioning and immobilization of the subject's head within the head coil. $\mathrm{T}_{2}{ }^{*}$ weighted images were obtained using a gradient-echo EPI sequence $\left(\mathrm{TR}=2040 \mathrm{msec}, \mathrm{TE}=26 \mathrm{msec}\right.$, flip angle $\left.=90^{\circ}\right)$ with 40 contiguous transverse slices of $3.3-\mathrm{mm}$ thickness covering the entire brain. Matrix size was $72 \times 72$ pixels with in-plane resolution of $2.67 \times 2.67 \mathrm{~mm}^{2}$, corresponding to a field of view of $192 \mathrm{~mm}$. A series of 965 whole-brain volume sets were acquired, with the first three images of each series being discarded.

High-resolution anatomical T1-weighted volume scans (MP-RAGE) were obtained in sagittal orientation $(\mathrm{TR}=2300$ msec, $\mathrm{TE}=3.03 \mathrm{msec}, \mathrm{TI}=900 \mathrm{msec}$, flip angle $=9^{\circ}, \mathrm{FOV}=256$ $\mathrm{mm}$, matrix $=256 \times 256$, number of sagittal slices $=192$, acceleration factor $[\mathrm{PAT}]=2, \mathrm{TA}=5: 21 \mathrm{~min}$, slice thickness $=1 \mathrm{~mm}$ ).

\section{Data analysis}

Performance was assessed by the percentage of correct reactions in each probability condition. A repeated-measures ANOVA with probability condition $(50 \%, 69 \%, 100 \%)$ as within-subject factor was performed to test for differences in performance between the three conditions. In previous work, we found short-term learning processes to be associated with exponential signal changes.
Therefore, an exponential decrease in the mean response times was modeled across each probability condition. This process can be expressed as a solution to the first-order differential equation $R(t)=p_{1}+p_{2}{ }^{*} \exp \left(-\left(1 / p_{3}\right) t\right)$, with $t=$ number of trials, $p_{1}=$ minimally attainable response time; $p_{2}$, the difference between starting level and maximum performance; and $p_{3}$, the learning rate time constant (Koch et al. 2007b). $p_{3}$ is dimensionless and describes the rate of response time change as a function of number of trials (i.e., the smaller the time constant $p_{3}$, the faster the response time, $R(t)$, decrease).

The goodness-of-fit for the probability-related learning curves was investigated by $\mathrm{R}^{2}$ corresponding to the best-fit curve derived by a nonlinear least squares approximation to the learning function.

FMRI data analysis was performed using SPM5 (http://www. fil.ion.ucl.ac.uk/spm).

Functional data were corrected for differences in acquisition time, realigned, linearly and nonlinearly normalized to the MNI reference brain, spatially smoothed with an 8-mm FWHM kernel, and high-pass filtered with a 128 -sec cut-off. All data were inspected for movement artifacts and did not exceed 3-mm translation on the $x_{-}, y_{-}$, or $z$-axis or $3^{\circ}$ rotation.

Brain activations were then analyzed voxel-wise to calculate statistical parametric maps of $t$-statistics for each condition: $50 \%$ (i.e., activation during responding to triangles and pentagons), $69 \%$ (i.e., activation during responding to circles and squares), $100 \%$ (i.e., activation during responding to half-moons and crosses), and feedback/reward condition (i.e., activation during presentation of correct solution and indication of reward or punishment modeled by separate regressors). A fixed effect model at the single-subject level was performed to create images of parameter estimates. Individual HRFs were modeled for the different probability conditions and the feedback/reward condition, and parameter estimates entered the GLM.

Second level analyses were based on a random-effects model. A one-way, nonsphericity-corrected, repeated-measures ANOVA with the three probability conditions as within-subject factor was performed on the second level. Here, the probabilityrelated activation changes were analyzed in association with both linearly increasing (i.e., $50 \%<69 \%<100 \%$ ) and linearly decreasing predictability (i.e., 50\% $>69 \%>100 \%$ ). Another oneway, nonsphericity-corrected, repeated-measures ANOVA served for analyzing the reward-related activation that was based on only positive feedback/reward (i.e., only correct reactions). Here, both time-invariant activation (i.e., activation during presentation of positive feedback without modeling of a decrease) and the linear decrease in activation in association with positive feedback/reward were analyzed. Analysis of the linear decrease was based on the prediction error concept that assumes greater activation when reward is less likely (Knutson et al. 2005). Against the background of our preceding studies, potential learningassociated signal changes were analyzed by adding the exponential signal decrease in each probability condition as a userspecified covariate on the first level.

The probability-specific exponential decrease in activation was likewise analyzed with a one-way, nonsphericity-corrected, repeated-measures ANOVA. All analyses were based on an FDRcorrected significance level of $P<0.05$.

\section{Acknowledgments}

This work was supported by an IZKF program grant of the FriedrichSchiller University of Jena/TMWFK (B307-04004) and the Bundesministerium für Bildung und Forschung BMBF (01ZZ0405; 01GW0740).

\section{References}

Abler, B., Walter, H., Erk, S., Kammerer, H., and Spitzer, M. 2006. Prediction error as a linear function of reward probability is coded in human nucleus accumbens. Neuroimage 31: 790-795.

Aron, A.R., Shohamy, D., Clark, J., Myers, C., Gluck, M.A., and Poldrack, R.A. 2004. Human midbrain sensitivity to cognitive feedback and uncertainty during classification learning. J. Neurophysiol. 
92: $1144-1152$.

Carter, C.S. and van Veen, V. 2007. Anterior cingulate cortex and conflict detection: An update of theory and data. Cogn. Affect. Behav. Neurosci. 7: 367-379.

Damasio, A.R., Grabowski, T.J., Bechara, A., Damasio, H., Ponto, L.L., Parvizi, J., and Hichwa, R.D. 2000. Subcortical and cortical brain activity during the feeling of self-generated emotions. Nat. Neurosci. 3: $1049-1056$

Daw, N.D., O'Doherty, J.P., Dayan, P., Seymour, B., and Dolan, R.J. 2006. Cortical substrates for exploratory decisions in humans. Nature 441: $876-879$.

Delgado, M.R., Nystrom, L.E., Fissell, C., Noll, D.C., and Fiez, J.A. 2000. Tracking the hemodynamic responses to reward and punishment in the striatum. J. Neurophysiol. 84: 3072-3077.

Delgado, M.R., Miller, M.M., Inati, S., and Phelps, E.A. 2005. An fMRI study of reward-related probability learning. Neuroimage 24: 862-873.

Elliott, R., Newman, J.L., Longe, O.A., and Deakin, J.F. 2003. Differential response patterns in the striatum and orbitofrontal cortex to financial reward in humans: A parametric functional magnetic resonance imaging study. J. Neurosci. 23: 303-307.

Hasselmo, M.E. and Stern, C.E. 2006. Mechanisms underlying working memory for novel information. Trends Cogn. Sci. 10: 487-493.

Heekeren, H.R., Wartenburger, I., Marschner, A., Mell, T., Villringer, A., and Reischies, F.M. 2007. Role of ventral striatum in reward-based decision making. Neuroreport 18: 951-955.

Hornak, J., O’Doherty, J., Bramham, J., Rolls, E.T., Morris, R.G., Bullock, P.R., and Polkey, C.E. 2004. Reward-related reversal learning after surgical excisions in orbito-frontal or dorsolateral prefrontal cortex in humans. J. Cogn. Neurosci. 16: 463-478.

Huettel, S.A., Song, A.W., and McCarthy, G. 2005. Decisions under uncertainty: Probabilistic context influences activation of prefrontal and parietal cortices. J. Neurosci. 25: 3304-3311.

Knutson, B., Fong, G.W., Bennett, S.M., Adams, C.M., and Hommer, D. 2003. A region of mesial prefrontal cortex tracks monetarily rewarding outcomes: Characterization with rapid event-related fMRI. Neuroimage 18: 263-272.

Knutson, B., Taylor, J., Kaufman, M., Peterson, R., and Glover, G. 2005. Distributed neural representation of expected value. J. Neurosci. 25: $4806-4812$.

Koch, K., Wagner, G., von Consbruch, K., Nenadic, I., Schultz, C., Ehle, C., Reichenbach, J., Sauer, H., and Schlosser, R. 2006. Temporal changes in neural activation during practice of information retrieval from short-term memory: An fMRI study. Brain Res. 1107: 140-150.

Koch, K., Pauly, K., Kellermann, T., Seiferth, N.Y., Reske, M., Backes, V., Stocker, T., Shah, N.J., Amunts, K., Kircher, T., et al. 2007a. Gender differences in the cognitive control of emotion: An fMRI study. Neuropsychologia 45: 2744-2754.

Koch, K., Wagner, G., Nenadic, I., Schachtzabel, C., Roebel, M., Schultz, C., Axer, M., Reichenbach, J.R., Sauer, H., and Schlosser, R.G. 2007b. Temporal modeling demonstrates preserved overlearning processes in schizophrenia: An fMRI study. Neuroscience 146: 1474-1483.
McClure, S.M., Berns, G.S., and Montague, P.R. 2003. Temporal prediction errors in a passive learning task activate human striatum. Neuron 38: 339-346.

Milham, M.P., Banich, M.T., Claus, E.D., and Cohen, N.J. 2003. Practice-related effects demonstrate complementary roles of anterior cingulate and prefrontal cortices in attentional control. Neuroimage 18: $483-493$.

Nieuwenhuis, S., Heslenfeld, D.J., von Geusau, N.J., Mars, R.B., Holroyd, C.B., and Yeung, N. 2005. Activity in human reward-sensitive brain areas is strongly context dependent. Neuroimage 25: 1302-1309.

O'Doherty, J.P., Hampton, A., and Kim, H. 2007. Model-based fMRI and its application to reward learning and decision making. Ann. N.Y. Acad. Sci. 1104: 35-53.

Oldfield, R. 1971. The assessment and analysis of handedness: The Edinburgh inventory. Neuropsychologia 9: 97-113.

Pagnoni, G., Zink, C.F., Montague, P.R., and Berns, G.S. 2002. Activity in human ventral striatum locked to errors of reward prediction. Nat. Neurosci. 5: 97-98.

Ridderinkhof, K.R., van den Wildenberg, W.P., Segalowitz, S.J., and Carter, C.S. 2004. Neurocognitive mechanisms of cognitive control: The role of prefrontal cortex in action selection, response inhibition, performance monitoring, and reward-based learning. Brain Cogn. 56: $129-140$.

Sakai, K. and Passingham, R.E. 2004. Prefrontal selection and medial temporal lobe reactivation in retrieval of short-term verbal information. Cereb. Cortex 14: 914-921.

Satterthwaite, T.D., Green, L., Myerson, J., Parker, J., Ramaratnam, M., and Buckner, R.L. 2007. Dissociable but inter-related systems of cognitive control and reward during decision making: Evidence from pupillometry and event-related fMRI. Neuroimage 37: 1017-1031.

Schultz, W. and Dickinson, A. 2000. Neuronal coding of prediction errors. Annu. Rev. Neurosci. 23: 473-500.

Tricomi, E., Delgado, M.R., McCandliss, B.D., McClelland, J.L., and Fiez, J.A. 2006. Performance feedback drives caudate activation in a phonological learning task. J. Cogn. Neurosci. 18: 1029-1043.

Waelti, P., Dickinson, A., and Schultz, W. 2001. Dopamine responses comply with basic assumptions of formal learning theory. Nature 412: $43-48$.

Yacubian, J., Glascher, J., Schroeder, K., Sommer, T., Braus, D.F., and Buchel, C. 2006. Dissociable systems for gain- and loss-related value predictions and errors of prediction in the human brain. J. Neurosci. 26: 9530-9537.

Yacubian, J., Sommer, T., Schroeder, K., Glascher, J., Braus, D.F., and Buchel, C. 2007. Subregions of the ventral striatum show preferential coding of reward magnitude and probability. Neuroimage 38: $557-563$.

Received June 16, 2008; accepted in revised form July 20, 2008. 


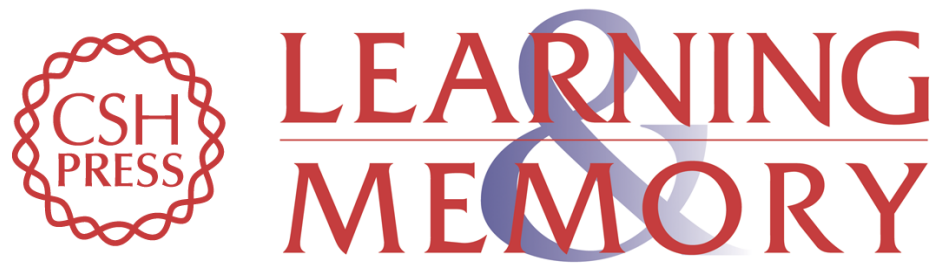

\section{The neural correlates of reward-related trial-and-error learning: An fMRI study with a probabilistic learning task}

Kathrin Koch, Claudia Schachtzabel, Gerd Wagner, et al.

Learn. Mem. 2008, 15:

Access the most recent version at doi:10.1101//m.1106408

References This article cites 31 articles, 4 of which can be accessed free at:

http://learnmem.cshlp.org/content/15/10/728.full.html\#ref-list-1

License

Email Alerting Receive free email alerts when new articles cite this article - sign up in the box at the Service top right corner of the article or click here. 